\title{
Phylogenetic Window Analysis for Detecting Chronological Changes in Natural Selection
}

\author{
Yoshiyuki Suzuki* \\ Center for Information Biology and DNA Data Bank of Japan, National Institute of Genetics, 1111 Yata, Mishima-shi, \\ Shizuoka-ken 411-8540, Japan
}

\begin{abstract}
Natural selection operating at the amino acid sequence level can be detected by comparing the rates of synonymous $\left(r_{\mathrm{S}}\right)$ and nonsynonymous $\left(r_{\mathrm{N}}\right)$ substitutions for the protein-coding nucleotide sequence, where relationships $r_{\mathrm{N}}>$ $r_{\mathrm{S}}$ and $r_{\mathrm{N}}<r_{\mathrm{S}}$ conventionally indicate positive and negative selection, respectively. The direction and magnitude of natural selection operating on a protein may change during evolution because the environmental conditions may vary along with time. Here a phylogenetic window analysis method is proposed for examining the chronological change in natural selection and for detecting natural selection that has operated temporarily in the phylogenetic tree. The phylogenetic window was defined as an interval between two time points in the phylogenetic tree, which was constructed under the assumption of a molecular clock. The total numbers of synonymous and nonsynonymous changes that have occurred for all the parts of branches overlapping with the window were compared to detect natural selection. When this method was applied to the analysis of the intra-host evolution for hypervariable region 1 of hepatitis $\mathrm{C}$ virus (HCV), which was known as the major target of humoral immunity, it was found that the pattern of chronological change in natural selection was heterogeneous among patients. The $r_{\mathrm{N}} / r_{\mathrm{S}}$ value was sometimes elevated temporarily, where positive selection was detected, suggesting that the antigenic evolution was punctuated during chronic infection of $\mathrm{HCV}$.
\end{abstract}

Keywords: Phylogenetic tree, window analysis, natural selection, synonymous substitution, nonsynonymous substitution, hepatitis $\mathrm{C}$ virus.

\section{INTRODUCTION}

Natural selection operating at the amino acid sequence level can be detected by comparing the rates of synonymous $\left(r_{\mathrm{S}}\right)$ (Supplementary Table S1) and nonsynonymous $\left(r_{\mathrm{N}}\right)$ substitutions for the protein-coding nucleotide sequence [1]. Under the assumption that the synonymous substitution is selectively nearly neutral, relationships $r_{\mathrm{N}}>r_{\mathrm{S}}$ and $r_{\mathrm{N}}<r_{\mathrm{S}}$ conventionally indicate positive and negative selection, respectively. The direction and magnitude of natural selection operating on a protein may change during evolution because the environmental conditions may vary along with time. To detect natural selection operating temporarily, it may be useful to compare $r_{\mathrm{S}}$ and $r_{\mathrm{N}}$ for a specific branch of the phylogenetic tree [2]. However, the numbers of synonymous $\left(c_{\mathrm{S}}\right)$ and nonsynonymous $\left(c_{\mathrm{N}}\right)$ changes that have occurred for a branch may not be large enough for a statistical test to detect a significant difference between $r_{\mathrm{S}}$ and $r_{\mathrm{N}}$. The branches where similar selection has operated may be grouped to increase the sensitivity of the test $[3,4]$, but it is difficult to determine such branches because the environmental condition for each branch is usually unknown.

Similar selection, however, may operate on the contemporary organisms sharing the environmental condition. For example, in the epidemics of human influenza A virus, evolution of hemagglutinin, which is the major target of humoral

*Address correspondence to this author at the Center for Information Biology and DNA Data Bank of Japan, National Institute of Genetics, 1111 Yata, Mishima-shi, Shizuoka-ken 411-8540, Japan; Tel: +81-55-981-6847; Fax: +81-55-981-6848; E-mail: yossuzuk@lab.nig.ac.jp immunity, has been characterized by long-intervals of antigenic stasis punctuated by short-intervals of antigenic changes $[5,6]$. In the former intervals, neutral and occasionally positively selected amino acid substitutions accumulate to provide the basis of antigenic innovations, whereas in the latter intervals, positive selection operates on parallel amino acid substitutions that cause antigenic changes for multiple lineages through epistasis with the substitutions that have accumulated in the former intervals [7]. Similarly, evolution of vesicular stomatitis virus has been characterized by genetic stasis and punctuated equilibrium, which were associated with small and large ecological changes, respectively [8, 9]. In addition, in the chronic infection of hepatitis $\mathrm{C}$ virus (HCV), it has been reported that positive selection operating on hypervariable region 1 (HVR1), which consists of the $\mathrm{N}$ terminal 27 amino acid sites of envelope glycoprotein 2 (E2) $[10,11]$ and is the major target of humoral immunity [12$15]$, reduced for the entire population in the course of 15.6 21.6 years of follow-up in 5 patients [16], although such a tendency was not found in other patients $[17,18]$.

In the above studies, the chronological change in natural selection has been inferred mainly based on the comparison of $r_{\mathrm{S}}$ and $r_{\mathrm{N}}$ for branches of the phylogenetic tree. However, since different branches were usually involved in different time intervals, it was difficult to detect natural selection operating for a specific time interval. For this purpose, contemporary parts of the branches across the phylogenetic tree may be grouped to conduct the test of selective neutrality. In the present study, the phylogenetic window analysis method was proposed for examining the chronological change in natural selection and for detecting natural selection that has operated 
temporarily in the phylogenetic tree. The method was applied to the data of the intra-host evolution for HVR1 of $\mathrm{HCV}$.

\section{MATERIALS AND METHODS}

\section{Phylogenetic Window Analysis}

The phylogenetic window analysis is intended to estimate the total values of $c_{\mathrm{S}}$ and $c_{\mathrm{N}}$ that have occurred for a specific time interval across the phylogenetic tree and conduct a test of selective neutrality for detecting natural selection. The phylogenetic tree is assumed to be known. To define specific time intervals, the phylogenetic tree is constructed under the assumption of a molecular clock, where the evolutionary rate is estimated by including calibration points or, particularly in the analysis of viral sequences, using the viral strains sampled at different time points [19]. The time scale of the phylogenetic tree is obtained by dividing the branch lengths by the evolutionary rate. In the phylogenetic tree, the ancestral nucleotide sequence at each interior node is inferred by the maximum parsimony (MP) [20, 21] or Bayesian [22, 23] method, and $c_{\mathrm{S}}$ and $c_{\mathrm{N}}$ for each branch are obtained by comparing the nucleotide sequence at its one end with the other [24]. The phylogenetic window is defined as an interval between two time points in the phylogenetic tree, where the length of the time interval corresponds to the window size $(w)$. The window overlaps with some branches of the phylogenetic tree. $c_{\mathrm{S}}$ and $c_{\mathrm{N}}$ for all the parts of branches overlapping with the window are summed to obtain the total numbers of synonymous $\left(c_{\mathrm{S}(\mathrm{W})}\right)$ and nonsynonymous $\left(c_{\mathrm{N}(\mathrm{W})}\right)$ changes that have occurred in the window, respectively. Here $c_{\mathrm{S}}$ and $c_{\mathrm{N}}$ for a part of a branch are obtained simply by fractionating these values for the branch according to the proportion of the overlapping region. The numbers of synonymous $\left(s_{\mathrm{S}}\right)$ and nonsynonymous $\left(s_{\mathrm{N}}\right)$ sites for the entire sequence are computed as the average of these values for all extant sequences. The null hypothesis of selective neutrality is tested by computing the probability $(p)$ of obtaining the observed or more biased values for $c_{\mathrm{S}(\mathrm{W})}$ and $c_{\mathrm{N}(\mathrm{W})}$ under the assumption that these values follow a binomial distribution with the probabilities of occurrence of synonymous and nonsynonymous changes given by $s_{\mathrm{S}} /\left(s_{\mathrm{S}}+s_{\mathrm{N}}\right)$ and $s_{\mathrm{N}} /\left(s_{\mathrm{S}}+s_{\mathrm{N}}\right)$, respectively [24]. Positive and negative selection are inferred when $c_{\mathrm{N}(\mathrm{W})} / s_{\mathrm{N}}>c_{\mathrm{S}(\mathrm{W})} / s_{\mathrm{S}}$ and $c_{\mathrm{N}(\mathrm{W})} / s_{\mathrm{N}}<c_{\mathrm{S}(\mathrm{W})} / s_{\mathrm{S}}$ with $p<0.05$, respectively. $\quad r_{\mathrm{N}} / r_{\mathrm{S}}$ for the window is estimated as $\left(c_{\mathrm{N}(\mathrm{W})} / s_{\mathrm{N}}\right) /\left(c_{\mathrm{S}(\mathrm{W})} / s_{\mathrm{S}}\right)$. The phylogenetic tree is scanned by sliding the window with a certain step size $(s)$ for examining the chronological change in natural selection and for detecting natural selection that has operated temporarily. It should be noted that, since multiple substitutions are not corrected for in this method, $c_{\mathrm{S}(\mathrm{W})}$ and $c_{\mathrm{N}(\mathrm{W})}$ may be underestimated, especially when the branch lengths of the phylogenetic tree are large. Therefore, this method is considered to be suitable for the analysis of closely related sequences. In the present study, however, the degree of underestimation appeared to be negligible for all the data analyzed because the branch lengths were generally small [25].

\section{Sequence Data}

The phylogenetic window analysis was applied to the data of the intra-host evolution for HCV. The data consisted of the 5'-terminal 324 nucleotide sites of the E2 gene, which encoded 108 amino acid sites corresponding to positions
384-491 of HCV-1 [26]. The first 27 amino acid sites (positions 384-410) corresponded to HVR1. The nucleotide sequences were derived from $13,7,17,5$, and 14 strains serially sampled from patients $1,2,3,4$, and 5, respectively, in the course of 15.6-21.6 years of follow-up during chronic infection [16]. The strain names, accession numbers in the International Nucleotide Sequence Database, and isolation years for these sequences are listed in Supplementary Table S2.

In a previous study, these sequences have been analyzed for examining the chronological change in natural selection [16]. The phylogenetic tree was constructed for the sequences obtained from each patient under the assumption of a molecular clock, and the $r_{\mathrm{N}} / r_{\mathrm{S}}$ value estimated for each branch was plotted against the time interval between the root of the phylogenetic tree and the middle of the branch. When the plots were superimposed for 5 patients, a negative correlation was observed between $r_{\mathrm{N}} / r_{\mathrm{S}}$ and the time interval. In addition, the $r_{\mathrm{N}} / r_{\mathrm{S}}$ value was found to be greater than 1 not only for HVR1 but also for amino acid positions 457-462.

In the present study, the phylogenetic window analysis was applied to the data obtained from each patient separately for examining whether the $r_{\mathrm{N}} / r_{\mathrm{S}}$ value reduced during chronic infection in every patient. It should be noted that the biological function of amino acid positions 457-462 is unknown. In addition, although both the humoral and cellular immunities against E2 were known to be effective to eliminate HCV [27-31], the latter immunity appeared to exert little effect on driving sequence evolution for E2 [18]. Therefore, only HVR1 (positions 384-410) was used for examining the chronological change in $r_{\mathrm{N}} / r_{\mathrm{S}}$ by the phylogenetic window analysis.

\section{Data Analysis}

The multiple alignment of the entire region (324 nucleotide sites) for the total of 56 sequences obtained from 5 patients was made using the computer program CLUSTAL W (version 1.83) [32]. The alignment did not contain any gaps. To determine the position of the root and the topology of the phylogenetic tree for the sequences obtained from each patient, the phylogenetic tree was constructed for the 56 sequences by the neighbor-joining (NJ) method [33] using the 324 nucleotide sites. The evolutionary distance was measured as the $\mathrm{p}$ distance, which was known to produce reliable topologies when large numbers of closely related sequences were analyzed [34, 35]. The reliability of each interior branch was assessed by the bootstrap method with 1000 resamplings [36]. MEGA (version 4.0) [37] was used for these analyses.

The branch lengths of the phylogenetic tree for the sequences obtained from each patient were re-estimated under the assumption of a molecular clock. Since the first $81 \mathrm{nu}-$ cleotide sites encoding HVR1 were examined for the chronological change in $r_{\mathrm{N}} / r_{\mathrm{S}}$, the molecular clock was not assumed to hold for these sites. Therefore, the remaining 243 nucleotide sites were used for estimating the branch lengths. The model of nucleotide substitution that best fitted these sites was judged by the hierarchical likelihood-ratio test (hLRT) using MODELTEST (version 3.7) [38]. Based on the best fit model, the branch lengths, transition/transversion rate ratio $(\kappa)$, and rate of nucleotide substitution were estimated under 
the assumption of the molecular clock by the maximum likelihood method using TIPDATE (version 1.2) [39]. In addition, the branch lengths and $\kappa$ were also estimated under the assumption of the rate heterogeneity among branches. The $\log$-likelihood $(\ln L)$ values obtained under these assumptions were compared by the LRT to test the null hypothesis of the molecular clock. Twice the difference in the $\ln L$ value was assumed to follow a $\chi^{2}$ distribution with a degree of freedom of $n-3$ [39], where $n$ denotes the number of sequences analyzed. The molecular clock was rejected if $p<0.05$.
The ancestral nucleotide sequence at each interior node of the phylogenetic tree was inferred by the MP method. The values of $s_{\mathrm{S}}$ and $s_{\mathrm{N}}$ were computed by taking into account the $\kappa$ value estimated above [40]. The phylogenetic window analysis was conducted for the sequences obtained from each patient using 5 years and 0.5 year as $w$ and $s(w=5$ and $s=$ $0.5)$, respectively, and using $w=10$ and $s=1$. In addition, the average pattern of the chronological change in natural selection for 5 patients was examined by summing the $c_{\mathrm{S}(\mathrm{W})}$ and $c_{\mathrm{N}(\mathrm{W})}$ values for the windows of the same chronological order and averaging the $s_{\mathrm{S}}$ and $s_{\mathrm{N}}$ values for 5 patients.

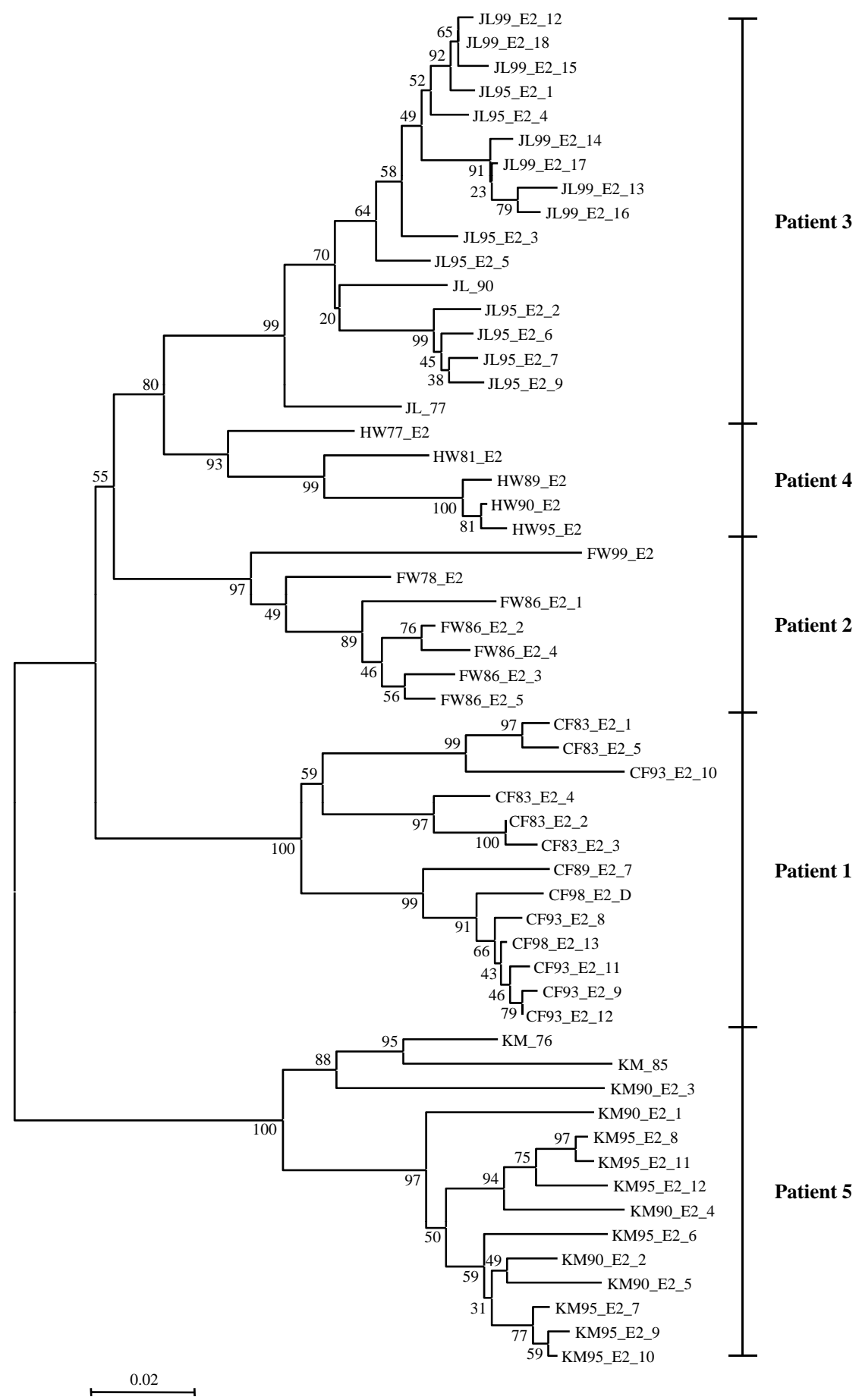

Fig. (1). Phylogenetic tree constructed for the total of $56 \mathrm{HCV}$ strains serially sampled from 5 patients. The bootstrap probability is indicated for each interior branch. The scale bar indicates 0.02 nucleotide substitution per site. 


\section{RESULTS}

\section{Construction of the Phylogenetic Tree}

The phylogenetic tree constructed for the total of 56 HCV strains serially sampled from 5 patients using the 5'terminal 324 nucleotide sites of the E2 gene is shown in Fig. (1). The strains obtained from each patient formed a single cluster, which was supported with a high bootstrap probability $(93 \%-100 \%)$. Using the position of the root and the topology of the sub-tree for each patient, the branch lengths were re-estimated with the 243 nucleotide sites, by eliminating the first 81 nucleotide sites that encoded HVR1. The models of nucleotide substitution best fitted to the 243 sites of the sequences obtained from patients 1, 2, 3, 4, and 5 were the model of Kimura [41] with the $\Gamma$ distribution for the rate heterogeneity among sites $(\mathrm{K}+\Gamma), \mathrm{K}, \mathrm{K}+\Gamma, \mathrm{K}$, and the model of Hasegawa et al. [42] $(\mathrm{HKY})+\Gamma$, respectively (Supplementary Table S3). Based on these models, the $\ln L$ values were obtained under the assumptions of the molecular clock and the rate heterogeneity among branches. When the null hypothesis of the molecular clock was tested for the sequences obtained from each patient, $p>0.05$ for all patients except for patient 3. However, even for patient $3, p=$ 0.0486, which was not statistically significant when the Bonferroni correction was conducted. These results indicated that the molecular clock could be assumed for the $243 \mathrm{nu}-$ cleotide sites of the sequences obtained from each patient.

\section{Results of the Phylogenetic Window Analysis}

The results of the phylogenetic window analysis conducted for 81 nucleotide sites that encoded HVR1 using the phylogenetic tree constructed for each patient as indicated above were shown in Fig. (2). Although the $r_{\mathrm{N}} / r_{\mathrm{S}}$ value for the same chronological region varied to some extent according to the window size assumed $(w=5$ or $w=10)$, the overall pattern of the chronological change in $r_{\mathrm{N}} / r_{\mathrm{S}}$ was similar between these two cases for each patient (Supplementary Table S4). In patient $1, r_{\mathrm{N}} / r_{\mathrm{S}}$ was initially greater than 1 , and decreased to be approximately 1 in the course of chronic infection. The $r_{\mathrm{N}} / r_{\mathrm{S}}$ value was large (25.783) for the last window with $w=5$. This result was obtained apparently because the $c_{\mathrm{S}}$ value was very small for this window (0.025) due to a statistical error (Supplementary Table S4). In fact, positive selection was not detected for this window and $r_{\mathrm{N}} / r_{\mathrm{S}}$ was not large for the corresponding window with $w=10$. Positive selection was not detected for the entire time period (Fig. 2; Supplementary Table S4). Similarly, in patient 2, $r_{\mathrm{N}} / r_{\mathrm{S}}$ was initially greater than 1 and decreased to be approximately 1 . However, the $r_{\mathrm{N}} / r_{\mathrm{S}}$ value slightly increased later, although positive selection was not detected for the entire time period. In contrast to the cases for patients 1 and $2, r_{\mathrm{N}} / r_{\mathrm{S}}$ was initially close to 1 in patient 3 . The $r_{\mathrm{N}} / r_{\mathrm{S}}$ value was elevated in the course of chronic infection, where positive selection was detected for 2 consecutive windows with $w=5$. However, the $r_{\mathrm{N}} / r_{\mathrm{S}}$ value later decreased to be approximately 1 . In patient $4, r_{\mathrm{N}} / r_{\mathrm{S}}$ was $\infty$ throughout the entire time period because only the nonsynonymous change was observed $\left(c_{\mathrm{S}}=0\right.$ and $\left.c_{\mathrm{N}}>0\right)$ for the entire phylogenetic tree. Positive selection was detected for 7 consecutive windows in the middle of the phylogenetic tree with $w=5$, and for 2 consecutive windows at the similar chronological region with $w=10$. In patient $5, r_{\mathrm{N}} / r_{\mathrm{S}}$ was initially greater than 1 , and decreased to be approximately 1 in the course of chronic infection. However, the $r_{\mathrm{N}} / r_{\mathrm{S}}$ value was elevated in the middle of the phylogenetic tree, where positive selection was detected for 10 consecutive windows with both $w=5$ and $w$ $=10$ at the similar chronological region. When the phylogenetic window analysis was conducted by combining the data from 5 patients, $r_{\mathrm{N}} / r_{\mathrm{S}}$ was initially greater than 1 , and gradually decreased toward 1 . However, positive selection was detected for most of the windows with both $w=5$ and $w=$ 10 .

\section{DISCUSSION}

\section{Problems in the Phylogenetic Window Analysis}

In the present study, the phylogenetic window analysis method was proposed for examining the chronological change in natural selection and for detecting natural selection that has operated temporarily in the phylogenetic tree, by estimating $c_{\mathrm{S}(\mathrm{W})}$ and $c_{\mathrm{N}(\mathrm{W})}$ and conducting the test of selective neutrality. However, there appeared to be some problems in this method. First, the window size should be large enough to include a sufficient number of nucleotide changes $\left(c_{\mathrm{S}(\mathrm{W})}+\right.$ $\left.c_{\mathrm{N}(\mathrm{W})}\right)$, which corresponded to the sample size in a statistical test, for obtaining a significant result. For example, in the analysis of the HCV strains isolated from patient 4, positive selection was detected with $w=10$ but not with $w=5$ at the same chronological region of the phylogenetic tree. Since $c_{\mathrm{S}(\mathrm{W})}=0$ for both cases, success or failure in detecting positive selection was determined by whether the sample size $\left(c_{\mathrm{N}(\mathrm{W})}\right)$ was sufficient for obtaining a statistical significance or not, respectively. The window size, however, should not be excessively large, because the effect of natural selection is averaged for the window and natural selection operating only for a short time interval may be obscured. For example, in the analysis of the sequences obtained from patient 3 , positive selection was detected with $w=5$ but not with $w=10$ at the same chronological region. In fact, the peak of the $r_{\mathrm{N}} / r_{\mathrm{S}}$ value observed with $w=5$ was obscured with $w=10$. In addition, the sample size for a window depends on the total length of the parts of branches included in the window. However, since the number of branches may vary along with the phylogenetic tree, the window size required for including a sufficient sample size to obtain a statistical significance may be different among chronological regions of the phylogenetic tree. For example, in the analysis of the sequences obtained from patient 4 , positive selection was detected with $w=10$ only in the middle of the phylogenetic tree, although $r_{\mathrm{N}} / r_{\mathrm{S}}$ was $\infty$ for the entire time period. These observations suggested that various window sizes should be examined in the analysis [43, 44], as was the case with the present study. Since the sample size varied among the windows and was sometimes insufficient for obtaining a statistical significance, the correction for multiple testing was not adopted in the present study.

Second, $c_{\mathrm{S}}$ and $c_{\mathrm{N}}$ for a part of a branch overlapping with the phylogenetic window were obtained simply by fractionating these values for the branch according to the proportion of the overlapping region, suggesting that the synonymous and nonsynonymous changes were implicitly assumed to be evenly distributed along with the branch. This assumption, however, may be inconsistent with the idea of the phylogenetic window analysis, where the chronological change in 
A

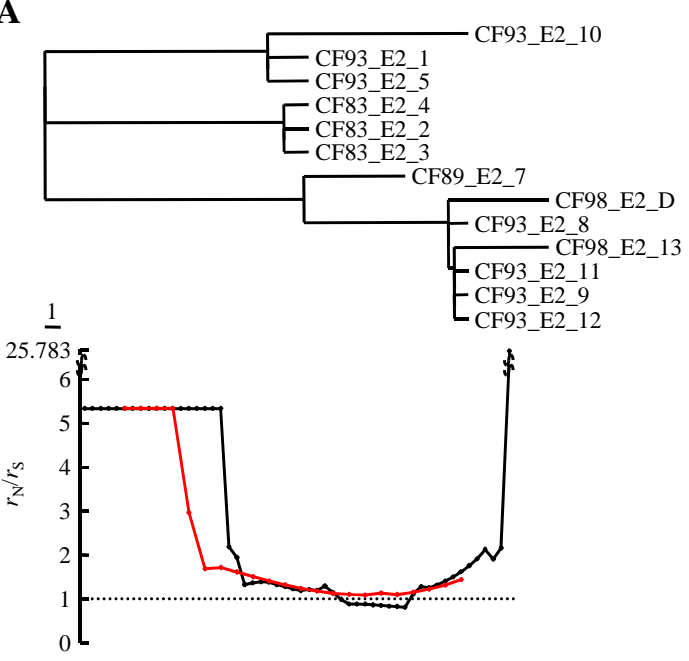

C

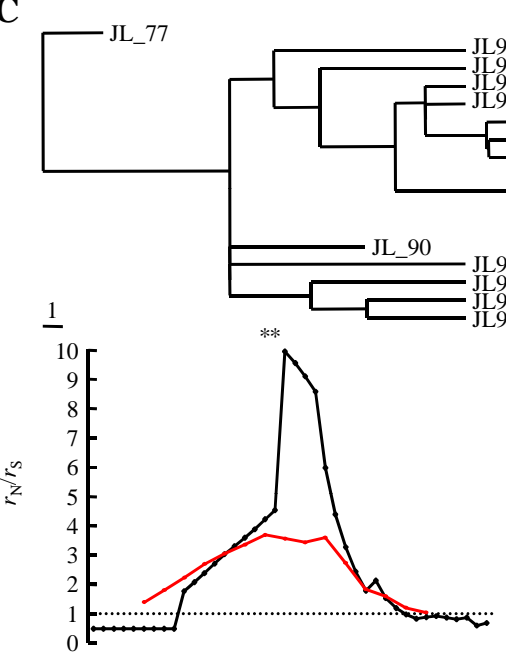

E

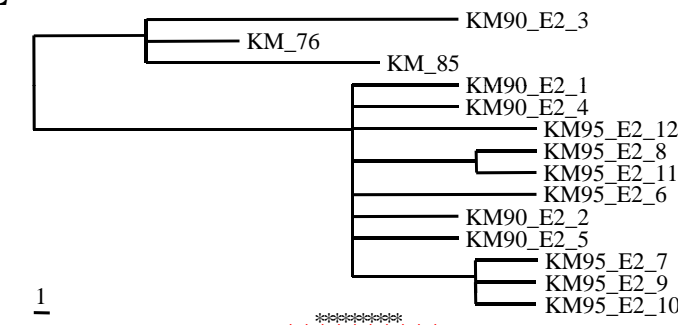

B

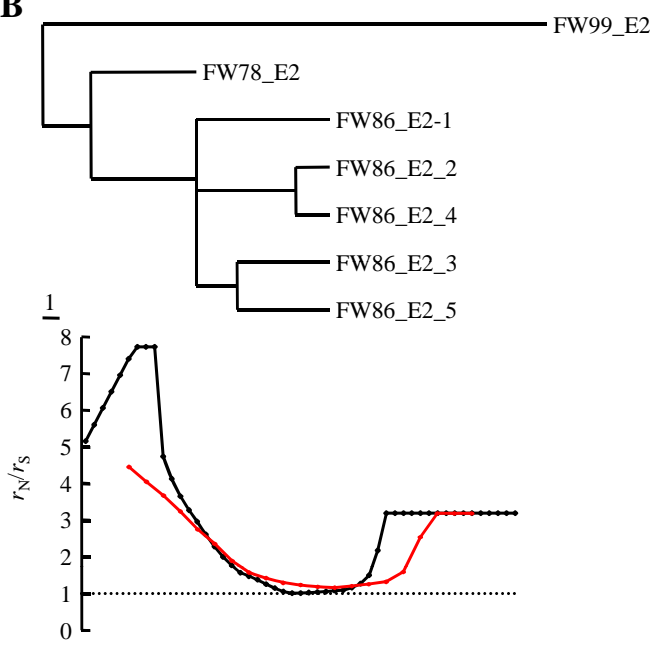

D
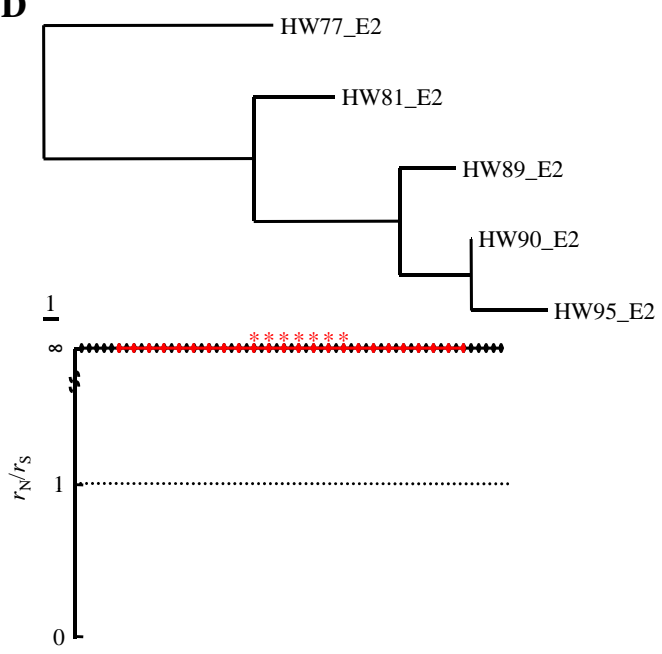

$\mathbf{F}$

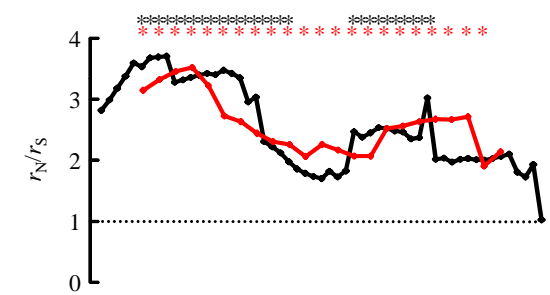

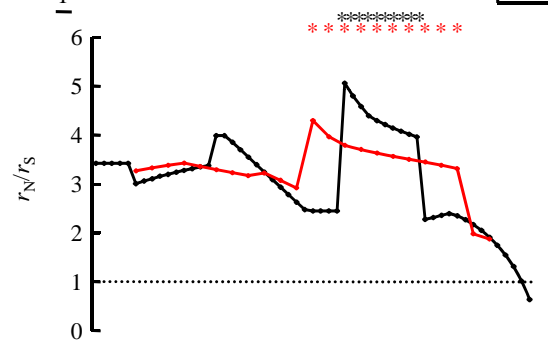

Fig. (2). Results of the phylogenetic window analysis conducted for HVR1 of the HCV strains sampled from patients 1 (A), 2 (B), 3 (C), 4 (D), and 5 (E). The phylogenetic tree was constructed under the assumption of the molecular clock, where the scale bar indicates 1 year. The time scale for the results of the phylogenetic window analysis is matched to that for the phylogenetic tree for each patient. The black and red lines indicate the $r_{\mathrm{N}} / r_{\mathrm{S}}$ values with $w=5$ and $s=0.5$ and with $w=10$ and $s=1$, respectively. The black and red asterisks indicate the central time points of the windows where positive selection was detected with $w=5$ and $w=10$, respectively. The results obtained by combining the data from 5 patients are also indicated $(\mathrm{F})$. The data for the last two windows and the last window were removed for $w=5$ and $w=10$, respectively, because $c_{\mathrm{S}(\mathrm{W})}$ was 0 and $c_{\mathrm{N}(\mathrm{W})}$ was very small (approximately 1) (Supplementary Table $\mathbf{S 4}$ ). 
$r_{\mathrm{N}} / r_{\mathrm{S}}$, which may occur at any time point irrespective of the position on the branch, was intended to be detected. Since the effect of natural selection is averaged for each branch, this method may produce conservative results for the extent of chronological change in $r_{\mathrm{N}} / r_{\mathrm{S}}$ and for the detection of natural selection. Nevertheless, this problem may disappear as more sequences become available in the analysis, so that the branch lengths become smaller in the phylogenetic tree, as in the case for influenza A virus [45-47].

\section{Punctuated Evolution of Antigenicity During Chronic Infection of $\mathrm{HCV}$}

When the phylogenetic window analysis was applied to the combined data of the intra-host evolution for HVR1 of $\mathrm{HCV}$ in 5 patients, it was found that the $r_{\mathrm{N}} / r_{\mathrm{S}}$ value decreased along with time, which was consistent with the previous study [16]. However, positive selection was detected for most of the windows, suggesting that escape mutants from the humoral immunity were generated with a decreasing rate throughout the chronic infection on average. The decrease in the rate of generating escape mutants may have occurred because strain-specific and low titer neutralizing antibodies (nAbs) are elicited in the early stage of HCV infection, whereas cross-reactive and high titer nAbs are elicited later [31, 48]. Alternatively, the humoral immunity against HCV may have diminished in the late stage of chronic infection, so that the selective pressure to generate escape mutants may have reduced [16]. In the present study, however, it was also found that the pattern of chronological change in natural selection was heterogeneous among patients $[17,18]$. The $r_{\mathrm{N}} / r_{\mathrm{S}}$ value was sometimes elevated temporarily even in the later stage, where positive selection was detected, indicating that the antigenic evolution was punctuated during chronic infection of HCV. The punctuated evolution of antigenicity, however, may result from different mechanisms according to the driving force of positive selection. If it is assumed that the viral population generally contains antigenic mutants abundantly and positive selection is governed mainly by the change in the environmental condition [49-51], as has been indicated for vesicular stomatitis virus [8,9], the above observation is considered to reflect the temporary change in the humoral immunity in the patients. On the other hand, if it is assumed that positive selection is governed mainly by de novo generation of antigenic mutants that can escape from the humoral immunity, as has been indicated for influenza A virus [5, 6, 52], the above observation is considered to reflect the epistasis among amino acid sites for determining the antigenicity. To distinguish these possibilities, it may be useful to compare the strength of immune responses in the patients as well as the degree of antigenic changes in HCV for the time intervals where positive selection was detected with those for other time intervals.

\section{ACKNOWLEDGEMENTS}

The author thanks anonymous reviewers for valuable comments. The present study was supported by KAKENHI 17770007 to Y.S.

\section{REFERENCES}

[1] Hughes, A.L.; Nei, M. Pattern of nucleotide substitution at major histocompatibility complex class I loci reveals overdominant selection. Nature, 1988, 335: 167-170.
[2] Zhang, J.; Rosenberg, H.F.; Nei, M. Positive Darwinian selection after gene duplication in primate ribonuclease genes. Proc. Natl. Acad. Sci. USA, 1998, 95: 3708-3713.

[3] Yang, Z. Likelihood ratio tests for detecting positive selection and application to primate lysozyme evolution. Mol. Biol. Evol., 1998, 15: 568-573.

[4] Yang, Z.; Nielsen, R. Synonymous and nonsynonymous rate variation in nuclear genes of mammals. J. Mol. Evol., 1998, 46: 409418.

[5] Smith, D.J.; Lapedes, A.S.; de Jong, J.C.; Bestebroer, T.M.; Rimmelzwaan, G.F.; Osterhaus, A.D.M.E.; Fouchier, R.A.M. Mapping the antigenic and genetic evolution of influenza virus. Science, 2004, 305; 371-376.

[6] Wolf, Y.I.; Viboud, C.; Holmes, E.C.; Koonin, E.V.; Lipman, D.J. Long intervals of stasis punctuated by bursts of positive selection in the seasonal evolution of influenza A virus. Biol. Direct, 2006, 1: 34.

[7] Shih, A.C.-C.; Hsiao, T.-C.; Ho, M.-S.; Li, W.-H. Simultaneous amino acid substitutions at antigenic sites drive influenza $\mathrm{A}$ hemagglutinin evolution. Proc. Natl. Acad. Sci. USA, 2007, 104: 6283-6288.

[8] Nichol, S.T.; Rowe, J.E.; Fitch, W.M. Punctuated equilibrium and positive Darwinian evolution in vesicular stomatitis virus. Proc. Natl. Acad. Sci. USA, 1993, 90: 10424-10428.

[9] Rodriguez, L.L.; Fitch, W.M.; Nichol, S.T. Ecological factors rather than temporal factors dominate the evolution of vesicular stomatitis virus. Proc. Natl. Acad. Sci. USA, 1996, 93: 1303013035 .

[10] Hijikata, M.; Kato, N.; Ootsuyama, Y.; Nakagawa, M.; Ohkoshi, S.; Shimotohno, K. Hypervariable regions in the putative glycoprotein of hepatitis C virus. Biochem. Biophys. Res. Commun., 1991, 175: 220-228.

[11] Weiner, A.J.; Brauer, M.J.; Rosenblatt, J.; Richman, K.H.; Tung, J.; Crawford, K.; Bonino, F.; Saracco, G.; Choo, Q.-L.; Houghton, M.; Han, J.H. Variable and hypervariable domains are found in the regions of $\mathrm{HCV}$ corresponding to the flavivirus envelope and NS1 proteins and the pestivirus envelope glycoproteins. Virology, 1991, 180: 842-848.

[12] Weiner, A.J.; Geysen, H.M.; Christopherson, C.; Hall, J.E.; Mason, T.J.; Saracco, G.; Bonino, F.; Crawford, K.; Marion, C.D.; Crawford, K.A.; Brunetto, M.; Barr, P.J.; Miyamura, T.; McHutchinson, J.; Houghton, M. Evidence for immune selection of hepatitis C virus (HCV) putative envelope glycoprotein variants: potential role in chronic HCV infections. Proc. Natl. Acad. Sci. USA, 1992, 89: 3468-3472.

[13] Farci, P.; Shimoda, A.; Wong, D.; Cabezon, T.; De Gioannis, D.; Strazzera, A.; Shimizu, Y.; Shapiro, M.; Alter, H.J.; Purcell, R.H. Prevention of hepatitis $\mathrm{C}$ virus infection in chimpanzees by hyperimmune serum against the hypervariable region 1 of the envelope 2 protein. Proc. Natl. Acad. Sci. USA, 1996, 93: 15394-15399.

[14] Zibert, A.; Kraas, W.; Meisel, H.; Jung, G.; Roggendorf, M. Epitope mapping of antibodies directed against hypervariable region 1 in acute self-limiting and chronic infections due to hepatitis $\mathrm{C}$ virus. J. Virol., 1997, 71: 4123-4127.

[15] Booth, J.C.; Kumar, U.; Webster, D.; Monjardino, J.; Thomas, H.C. Comparison of the rate of sequence variation in the hypervariable region of E2/NS1 region of hepatitis C virus in normal and hypogammaglobulinemic patients. Hepatology, 1998, 27: 223-227.

[16] Hanada, K.; Tanaka, Y.; Mizokami, M.; Gojobori, T.; Alter, H.J. A reduction in selective immune pressure during the course of chronic hepatitis $\mathrm{C}$ correlates with diminished biochemical evidence of hepatic inflammation. Virology, 2007, 361: 27-33.

[17] Chen, S.; Wang, Y.-M. Multigene tracking of quasispecies in viral persistence and clearance of hepatitis C virus. World J. Gastroenterol., 2005, 11: 2874-2884.

[18] Kuntzen, T.; Timm, J.; Berical, A.; Lewis-Ximenez, L.L.; Jones, A.; Nolan, B.; zur Wiesch, J.S.; Li, B.; Schneidewind, A.; Kim, A.Y.; Chung, R.T.; Lauer, G.M.; Allen, T.M. Viral sequence evolution in acute hepatitis C virus infection. J. Virol., 2007, 81: 1165811668.

[19] Nei, M. Genetic polymorphism and the role of mutation in evolution. In Evolution of Genes and Proteins.; Nei, M.; Koehn, R.K. Eds.; Sinauer: Sunderland, Mass, 1981; pp. 165-190.

[20] Fitch, W.M. Toward defining the course of evolution: minimum change for a specific tree topology. Syst. Zool., 1971, 20: 406-416. 
[21] Hartigan, J.A. Minimum mutation fits to a given tree. Biometrics, 1973, 29: 53-65.

[22] Yang, Z.; Kumar, S.; Nei, M. A new method of inference of ancestral nucleotide and amino acid sequences. Genetics, 1995, 141: 1641-1650.

[23] Zhang, J.; Nei, M. Accuracies of ancestral amino acid sequences inferred by the parsimony, likelihood, and distance methods. $J$. Mol. Evol., 1997, 44: S139-S146.

[24] Suzuki, Y.; Gojobori, T. A method for detecting positive selection at single amino acid sites. Mol. Biol. Evol., 1999, 16: 1315-1328.

[25] Saitou, N. A theoretical study of the underestimation of branch lengths by the maximum parsimony principle. Sys. Zool., 1989, 38 : $1-6$.

[26] Choo, Q.-L.; Richman, K.; Han, J.H.; Berger, K.; Lee, C.; Dong, C.; Gallegos, C.; Coit, D.; Medina-Selby, A.; Barr, P.J.; Weiner, A.; Bradley, D.W.; Kuo, G.; Houghton, M. Genetic organization and diversity of the hepatitis C virus. Proc. Natl. Acad. Sci. USA, 1991, 88: 2451-2455.

[27] Suzuki, Y.; Gojobori, T. Positively selected amino acid sites in the entire coding region of hepatitis C virus subtype $1 \mathrm{~b}$. Gene, 2001, 276: 83-87.

[28] Brown, R.J.P.; Juttla, V.S.; Tarr, A.W.; Finnis, R.; Irving, W.L.; Hemsley, S.; Flower, D.R.; Borrow, P.; Ball, J.K. Evolutionary dynamics of hepatitis $C$ virus envelope genes during chronic infection. J. Gen. Virol., 2005, 86: 1931-1942.

[29] Suzuki, Y. New methods for detecting positive selection at single amino acid sites. J. Mol. Evol., 2004, 59: 11-19.

[30] Sheridan, I.; Pybus, O.G.; Holmes, E.C.; Klenerman, P. Highresolution phylogenetic analysis of hepatitis $\mathrm{C}$ virus adaptation and its relationship to disease progression. J. Virol., 2004, 78: 34473454 .

[31] von Hahn, T.; Yoon, J.C.; Alter, H.; Rice, C.M.; Rehermann, B.; Balfe, P.; McKeating, J.A. Hepatitis C virus continuously escapes from neutralizing antibody and $\mathrm{T}$-cell responses during chronic infection in vivo. Gastroenterology, 2007, 132: 667-678.

[32] Thompson, J.D.; Higgins, D.G.; Gibson, T.J. CLUSTAL W: improving the sensitivity of progressive multiple-sequence alignment through sequence weighting, position-specific gap penalties, and weight-matrix choice. Nucleic Acids Res., 1994, 22: 4673-4680.

[33] Saitou, N.; Nei, M. The neighbor-joining method: a new method for reconstructing phylogenetic trees. Mol. Biol. Evol., 1987, 4: 406-425.

[34] Nei, M.; Kumar, S. Molecular Evolution and Phylogenetics, Oxford University Press: Oxford, New York, 2000.

[35] Takahashi, K.; Nei, M. Efficiencies of fast algorithms of phylogenetic inference under the criteria of maximum parsimony, minimum evolution, and maximum likelihood when a large number of sequences are used. Mol. Biol. Evol., 2000, 17: 1251-1258.

[36] Felsenstein, J. Confidence limits on phylogenies: an approach using the bootstrap. Evolution, 1985, 39: 783-791.

[37] Tamura, K.; Dudley, J.; Nei, M.; Kumar, S. MEGA4: molecular evolutionary genetics analysis (MEGA) software version 4.0. Mol. Biol. Evol., 2007, 24: 1596-1599.
[38] Posada, D.; Crandall, K.A. MODELTEST: testing the model of DNA substitution. Bioinformatics, 1998, 14: 817-818.

[39] Rambaut, A. Estimating the rate of molecular evolution: incorporating non-contemporaneous sequences into maximum likelihood phylogenies. Bioinformatics, 2000, 16: 395-399.

[40] Suzuki, Y. Molecular Evolution of Pathogenic Viruses. PhD thesis. The Graduate University for Advanced Studies, School of Life Science, Department of Genetics, 1999.

[41] Kimura, M. A simple method for estimating evolutionary rate of base substitution through comparative studies of nucleotide sequences. J. Mol. Evol., 1980, 16: 111-120.

[42] Hasegawa, M.; Kishino, H.; Yano, T. Dating of the human-ape splitting by a molecular clock of mitochondrial DNA. J. Mol. Evol., 1985, 22: 160-174.

[43] Fares, M.A.; Elena, S.F.; Ortiz, J.; Moya, A.; Barrio, E. A sliding window-based method to detect selective constraints in proteincoding genes and its application to RNA viruses. J. Mol. Evol., 2002, 55: 509-521.

[44] Suzuki, Y. Three-dimensional window analysis for detecting positive selection at structural regions of proteins. Mol. Biol. Evol., 2004, 21: 2352-2359.

[45] Ghedin, E.; Sengamalay, N.A.; Shumway, M.; Zaborsky, J.; Feldblyum, T.; Subbu, V.; Spiro, D.J.; Sitz, J.; Koo, H.; Bolotov, P.; Dernovoy, D.; Tatusova, T.; Bao, Y.; St. George, K.; Taylor, J.; Lipman, D.J.; Fraser, C.M.; Taubenberger, J.K.; Salzberg, S.L. Large-scale sequencing of human influenza reveals the dynamic nature of viral genome evolution. Nature, 2005, 437: 1162-1166.

[46] Holmes, E.C.; Ghedin, E.; Miller, N.; Taylor, J.; Bao, Y.; St. George, K.; Grenfell, B.T.; Salzberg, S.L.; Fraser, C.M.; Lipman, D.J.; Taubenberger, J.K. Whole-genome analysis of human influenza A virus reveals multiple persistent lineages and reassortment among recent H3N2 viruses. PLoS Biol., 2005, 3: e300.

[47] Suzuki, Y. Natural selection on the influenza virus genome. Mol. Biol. Evol., 2006, 23: 1902-1911.

[48] Logvinoff, C.; Major, M.E.; Oldach, D.; Heyward, S.; Talal, A.; Balfe, P.; Feinstone, S.M.; Alter, H.; Rice, C.M.; McKeating, J.A. Neutralizing antibody response during acute and chronic hepatitis C virus infection. Proc. Natl. Acad. Sci. USA, 2004, 101: 1014910154.

[49] Eigen, M.; Schuster, P. A principle of natural self-organization. Naturwissenschaften, 1977, 64: 541-565.

[50] Martell, M.; Esteban, J.; Quer, J.; Genesca, J.; Weiner, A.; Esteban, R.; Guardia, J.; Gomez, J. Hepatitis C virus (HCV) circulates as a population of different but closely related genomes: quasispecies nature of HCV genome distribution. J. Virol., 1992, 66: 3225-3229.

[51] Fernandez, J.; Taylor, D.; Morhardt, D.R.; Mihalik, K.; Puig, M.; Rice, C.M.; Feinstone, S.M.; Major, M.E. Long-term persistence of infection in chimpanzees inoculated with an infectious hepatitis $\mathrm{C}$ virus clone is associated with a decrease in the viral amino acid substitution rate and low levels of heterogeneity. J. Virol., 2004, 78: 9782-9789.

[52] Nei, M. The new mutation theory of phenotypic evolution. Proc. Natl. Acad. Sci. USA, 2007, 104: 12235-12242. 


\section{SUPPLEMENTARY MATERIALS}

Table S1. List of Abbreviations Used in the Present Paper

\begin{tabular}{|c|c|}
\hline$r_{\mathrm{S}}\left(r_{\mathrm{N}}\right)$ & Rate of synonymous (nonsynonymous) substitution \\
\hline$c_{\mathrm{S}(\mathrm{W})}\left(c_{\mathrm{N}(\mathrm{W})}\right)$ & Number of synonymous (nonsynonymous) changes for the phylogenetic window \\
\hline$s_{\mathrm{S}}\left(s_{\mathrm{N}}\right)$ & Number of synonymous (nonsynonymous) sites \\
\hline$s$ & Step size \\
\hline$p$ & Probability \\
\hline$n$ & Number of sequences \\
\hline$\kappa$ & Transition/transversion rate ratio \\
\hline NJ & Neighbor-joining \\
\hline $\mathrm{K}$ & Model of Kimura \\
\hline HKY & Model of Hasegawa et al. \\
\hline$\Gamma$ & $\Gamma$ distribution for the rate heterogeneity among sites \\
\hline $\mathrm{HCV}$ & Hepatitis $\mathrm{C}$ virus \\
\hline HVR1 & Hypervariable region 1 \\
\hline E2 & Envelope glycoprotein 2 \\
\hline $\mathrm{nAb}$ & Neutralizing antibody \\
\hline
\end{tabular}

Table S2. Strain Names, Accession Numbers in the International Nucleotide Sequence Database, and Isolation Years for the Sequences Obtained from 5 Patients Analyzed in the Present Study [16]

\begin{tabular}{|c|c|c|c|c|c|c|c|}
\hline \multirow[t]{8}{*}{1} & CF83_E2_1 & AB272166 & 1983 & & JL95_E2_7 & AB272200 & 1995 \\
\hline & CF83_E2_3 & AB272168 & 1983 & & JL99_E2_12 & AB272204 & 1999 \\
\hline & CF83_E2_4 & AB272169 & 1983 & & JL99_E2_13 & AB272205 & 1999 \\
\hline & CF89_E2_7 & AB272172 & 1989 & & JL99_E2_15 & AB272207 & 1999 \\
\hline & CF93_E2_8 & AB272173 & 1993 & & JL99_E2_16 & AB272208 & 1999 \\
\hline & CF93_E2_9 & AB272174 & 1993 & & JL99_E2_17 & AB272209 & 1999 \\
\hline & CF93_E2_10 & AB272175 & 1993 & & JL99_E2_18 & AB272210 & 1999 \\
\hline & CF98_E2_D & AB272179 & 1998 & & HW90_E2 & AB272190 & 1990 \\
\hline \multirow[t]{2}{*}{2} & FW78_E2 & AB272180 & 1978 & & HW95_E2 & AB272191 & 1995 \\
\hline & FW99_E2 & AB272181 & 1999 & 5 & KM_76 & AB272212 & 1976 \\
\hline
\end{tabular}


(Table S2). Contd.....

\begin{tabular}{|c|c|c|c|c|c|c|c|}
\hline Patient & Strain name & Accession number & Isolation year & Patient & Strain name & Accession number & Isolation year \\
\hline & FW86_E2_1 & AB272182 & 1986 & & KM_85 & AB272213 & 1985 \\
\hline & FW86_E2_2 & AB272183 & 1986 & & KM90_E2_1 & AB272214 & 1990 \\
\hline & FW86_E2_3 & AB272184 & 1986 & & KM90_E2_2 & AB272215 & 1990 \\
\hline & FW86_E2_4 & AB272185 & 1986 & & KM90_E2_3 & AB272216 & 1990 \\
\hline & FW86_E2_5 & AB272186 & 1986 & & KM90_E2_4 & AB272217 & 1990 \\
\hline \multirow[t]{8}{*}{3} & JL_77 & AB272192 & 1977 & & KM90_E2_5 & AB272218 & 1990 \\
\hline & JL_90 & AB272193 & 1990 & & KM95_E2_6 & AB272219 & 1995 \\
\hline & JL95_E2_1 & AB272194 & 1995 & & KM95_E2_7 & AB272220 & 1995 \\
\hline & JL95_E2_2 & AB272195 & 1995 & & KM95_E2_8 & AB272221 & 1995 \\
\hline & JL95_E2_3 & AB272196 & 1995 & & KM95_E2_9 & AB272222 & 1995 \\
\hline & JL95_E2_4 & AB272197 & 1995 & & KM95_E2_10 & AB272223 & 1995 \\
\hline & JL95_E2_5 & AB272198 & 1995 & & KM95_E2_11 & AB272224 & 1995 \\
\hline & JL95_E2_6 & AB272199 & 1995 & & KM95_E2_12 & AB272225 & 1995 \\
\hline
\end{tabular}

Table S3. Results of the Analysis Using the 243 Nucleotide Sites of the E2 Gene for the HCV Strains Serially Sampled from 5 Patients

\begin{tabular}{|c|c|c|c|c|c|c|c|c|}
\hline Patient & Best fit model & $\ln L$ with clock & $\ln L$ without clock & $\boldsymbol{p}$ value in the LRT & $\kappa$ & $\boldsymbol{s}_{\mathrm{S}}$ & $\boldsymbol{s}_{\mathrm{N}}$ & Rate (per site per year) \\
\hline \hline 1 & $\mathrm{~K}+\Gamma$ & -567.824 & -562.473 & 0.381 & 4.891 & 24.558 & 56.442 & 0.00176 \\
\hline 2 & $\mathrm{~K}$ & -480.792 & -476.947 & 0.104 & 4.991 & 24.548 & 56.452 & 0.00131 \\
\hline 3 & $\mathrm{~K}+\Gamma$ & -575.739 & -563.844 & 0.0486 & 4.022 & 24.597 & 56.403 & 0.00142 \\
\hline 4 & $\mathrm{~K}$ & -440.897 & -440.572 & 0.723 & 4.057 & 24.393 & 56.607 & 0.00133 \\
\hline 5 & $\mathrm{HKY}+\Gamma$ & -642.695 & -638.245 & 0.631 & 5.474 & 24.261 & 56.739 & 0.00161 \\
\hline
\end{tabular}

Table S4. The $c_{\mathrm{S}(\mathrm{W})}, c_{\mathrm{N}(\mathrm{W})}$, and $r_{\mathrm{N}} / r_{\mathrm{S}}$ Values for each Phylogenetic Window

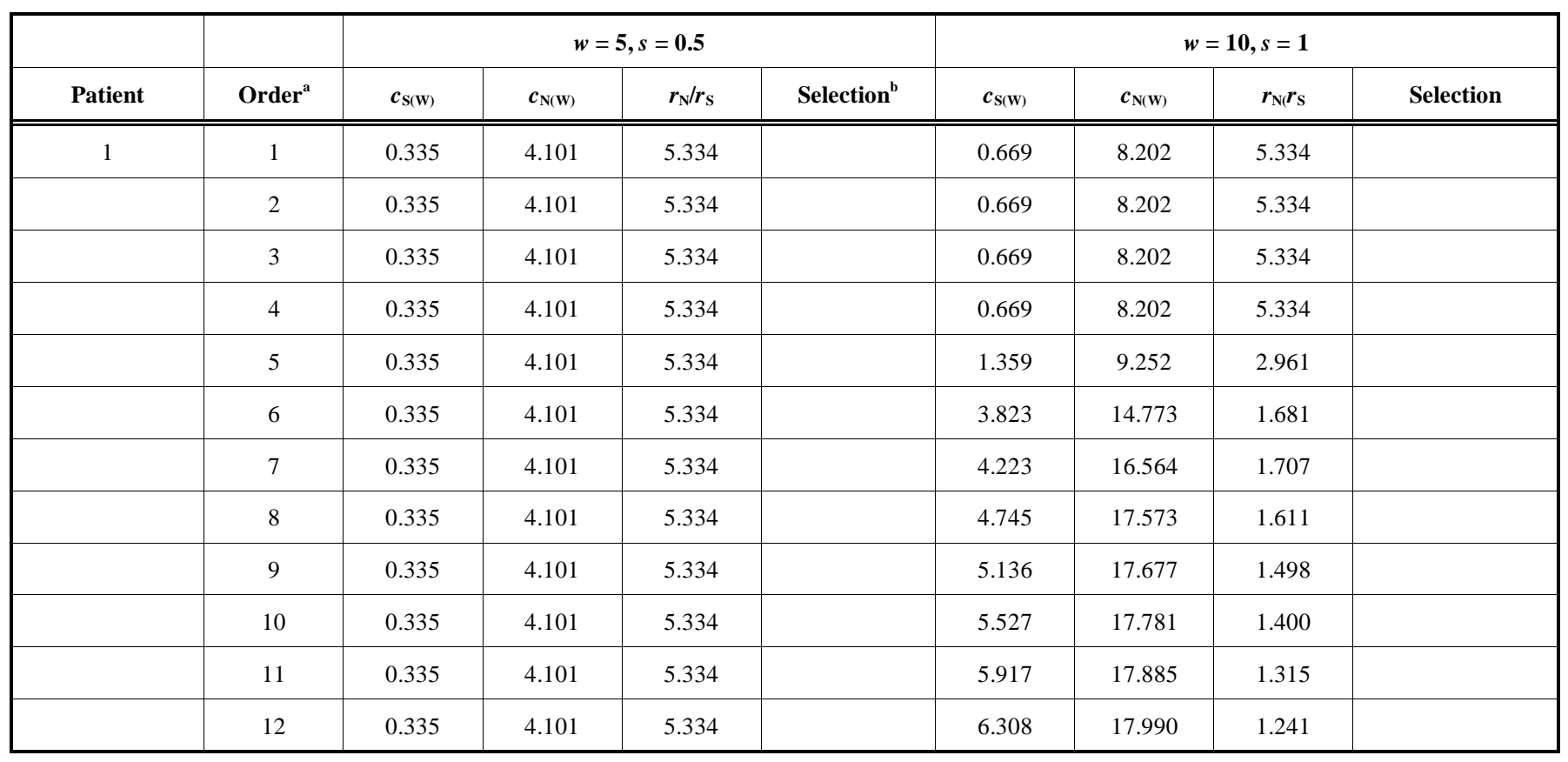




\begin{tabular}{|c|c|c|c|c|c|c|c|c|c|}
\hline \multirow[b]{2}{*}{ Patient } & \multirow[b]{2}{*}{ Order $^{a}$} & \multicolumn{4}{|c|}{$w=5, s=0.5$} & \multicolumn{4}{|c|}{$w=10, s=1$} \\
\hline & & $c_{\mathrm{S}(\mathrm{W})}$ & $c_{\mathrm{N}(\mathrm{W})}$ & $r_{\mathrm{N}} / r_{\mathrm{S}}$ & Selection $^{b}$ & $c_{\mathrm{S}(\mathbf{W})}$ & $c_{\mathrm{N}(\mathrm{W})}$ & $r_{\mathrm{N}(} r_{\mathrm{S}}$ & Selection \\
\hline & 13 & 0.335 & 4.101 & 5.334 & & 6.699 & 18.094 & 1.175 & \\
\hline & 14 & 0.335 & 4.101 & 5.334 & & 7.016 & 17.987 & 1.116 & \\
\hline & 15 & 0.335 & 4.101 & 5.334 & & 6.558 & 16.594 & 1.101 & \\
\hline & 16 & 0.335 & 4.101 & 5.334 & & 4.328 & 10.730 & 1.079 & \\
\hline & 17 & 0.335 & 4.101 & 5.334 & & 4.579 & 11.891 & 1.130 & \\
\hline & 18 & 0.335 & 4.101 & 5.334 & & 4.454 & 11.192 & 1.093 & \\
\hline & 19 & 1.025 & 5.151 & 2.187 & & 3.996 & 10.561 & 1.150 & \\
\hline & 20 & 1.258 & 5.639 & 1.950 & & 3.538 & 9.929 & 1.221 & \\
\hline & 21 & 3.488 & 10.672 & 1.331 & & 3.080 & 9.298 & 1.313 & \\
\hline & 22 & 3.689 & 11.567 & 1.364 & & 2.622 & 8.666 & 1.438 & \\
\hline & 23 & 3.889 & 12.463 & 1.394 & & & & & \\
\hline & 24 & 4.203 & 13.369 & 1.384 & & & & & \\
\hline & 25 & 4.410 & 13.472 & 1.329 & & & & & \\
\hline & 26 & 4.606 & 13.524 & 1.278 & & & & & \\
\hline & 27 & 4.801 & 13.576 & 1.230 & & & & & \\
\hline & 28 & 4.997 & 13.628 & 1.187 & & & & & \\
\hline & 29 & 4.502 & 12.631 & 1.221 & & & & & \\
\hline & 30 & 4.464 & 12.194 & 1.189 & & & & & \\
\hline & 31 & 2.429 & 7.214 & 1.292 & & & & & \\
\hline & 32 & 2.424 & 6.370 & 1.143 & & & & & \\
\hline & 33 & 2.420 & 5.527 & 0.994 & & & & & \\
\hline & 34 & 2.300 & 4.672 & 0.884 & & & & & \\
\hline & 35 & 2.289 & 4.622 & 0.879 & & & & & \\
\hline & 36 & 2.289 & 4.622 & 0.879 & & & & & \\
\hline & 37 & 2.215 & 4.411 & 0.867 & & & & & \\
\hline & 38 & 2.136 & 4.188 & 0.853 & & & & & \\
\hline & 39 & 2.057 & 3.964 & 0.839 & & & & & \\
\hline & 40 & 1.978 & 3.740 & 0.823 & & & & & \\
\hline & 41 & 1.899 & 3.516 & 0.806 & & & & & \\
\hline & 42 & 1.951 & 5.026 & 1.121 & & & & & \\
\hline & 43 & 2.160 & 6.364 & 1.282 & & & & & \\
\hline & 44 & 2.368 & 6.840 & 1.257 & & & & & \\
\hline & 45 & 2.165 & 6.570 & 1.321 & & & & & \\
\hline & 46 & 1.936 & 6.254 & 1.406 & & & & & \\
\hline & 47 & 1.781 & 6.149 & 1.502 & & & & & \\
\hline & 48 & 1.631 & 6.057 & 1.616 & & & & & \\
\hline & 49 & 1.481 & 5.965 & 1.752 & & & & & \\
\hline
\end{tabular}


(Table S4). Contd.....

\begin{tabular}{|c|c|c|c|c|c|c|c|c|c|}
\hline \multirow[b]{2}{*}{ Patient } & \multirow[b]{2}{*}{ Order $^{a}$} & \multicolumn{4}{|c|}{$w=5, s=0.5$} & \multicolumn{4}{|c|}{$w=10, s=1$} \\
\hline & & $c_{\mathrm{S}(\mathbf{W})}$ & $c_{\mathrm{N}(\mathrm{W})}$ & $r_{N} / r_{S}$ & Selection $^{\mathbf{b}}$ & $c_{\mathrm{S}(\mathbf{W})}$ & $c_{\mathrm{N}(\mathrm{W})}$ & $r_{\mathrm{N}(} r_{\mathrm{S}}$ & Selection \\
\hline & 50 & 1.331 & 5.873 & 1.920 & & & & & \\
\hline & 51 & 1.181 & 5.781 & 2.129 & & & & & \\
\hline & 52 & 0.900 & 3.956 & 1.913 & & & & & \\
\hline & 53 & 0.463 & 2.302 & 2.165 & & & & & \\
\hline & 54 & 0.025 & 1.511 & 25.783 & & & & & \\
\hline \multirow[t]{32}{*}{2} & 1 & 0.508 & 6.020 & 5.152 & & 1.563 & 16.045 & 4.464 & \\
\hline & 2 & 0.509 & 6.564 & 5.606 & & 1.812 & 16.920 & 4.060 & \\
\hline & 3 & 0.510 & 7.108 & 6.058 & & 2.077 & 17.590 & 3.683 & \\
\hline & 4 & 0.511 & 7.652 & 6.508 & & 2.372 & 17.721 & 3.249 & \\
\hline & 5 & 0.512 & 8.196 & 6.957 & & 2.665 & 16.905 & 2.759 & \\
\hline & 6 & 0.513 & 8.741 & 7.404 & & 2.957 & 16.088 & 2.366 & \\
\hline & 7 & 0.514 & 9.144 & 7.733 & & 3.654 & 16.011 & 1.905 & \\
\hline & 8 & 0.514 & 9.144 & 7.733 & & 4.434 & 16.086 & 1.577 & \\
\hline & 9 & 0.514 & 9.144 & 7.733 & & 4.568 & 14.970 & 1.425 & \\
\hline & 10 & 0.931 & 10.132 & 4.731 & & 4.515 & 13.511 & 1.301 & \\
\hline & 11 & 1.055 & 10.025 & 4.133 & & 3.922 & 11.171 & 1.238 & \\
\hline & 12 & 1.178 & 9.919 & 3.660 & & 3.623 & 9.925 & 1.191 & \\
\hline & 13 & 1.302 & 9.812 & 3.277 & & 3.307 & 8.885 & 1.168 & \\
\hline & 14 & 1.426 & 9.706 & 2.961 & & 2.962 & 8.243 & 1.210 & \\
\hline & 15 & 1.565 & 9.394 & 2.611 & & 2.617 & 7.601 & 1.263 & \\
\hline & 16 & 1.711 & 8.985 & 2.284 & & 2.271 & 6.959 & 1.332 & \\
\hline & 17 & 1.858 & 8.577 & 2.008 & & 1.522 & 5.578 & 1.593 & \\
\hline & 18 & 2.004 & 8.169 & 1.773 & & 0.690 & 4.044 & 2.550 & \\
\hline & 19 & 2.150 & 7.761 & 1.569 & & 0.504 & 3.702 & 3.196 & \\
\hline & 20 & 1.880 & 6.365 & 1.472 & & 0.504 & 3.702 & 3.196 & \\
\hline & 21 & 1.903 & 6.063 & 1.386 & & 0.504 & 3.702 & 3.196 & \\
\hline & 22 & 2.086 & 6.054 & 1.262 & & & & & \\
\hline & 23 & 2.352 & 6.198 & 1.146 & & & & & \\
\hline & 24 & 2.619 & 6.343 & 1.053 & & & & & \\
\hline & 25 & 2.870 & 6.692 & 1.014 & & & & & \\
\hline & 26 & 2.883 & 6.713 & 1.013 & & & & & \\
\hline & 27 & 2.710 & 6.392 & 1.026 & & & & & \\
\hline & 28 & 2.538 & 6.071 & 1.040 & & & & & \\
\hline & 29 & 2.365 & 5.750 & 1.057 & & & & & \\
\hline & 30 & 2.192 & 5.429 & 1.077 & & & & & \\
\hline & 31 & 2.020 & 5.108 & 1.100 & & & & & \\
\hline & 32 & 1.687 & 4.494 & 1.158 & & & & & \\
\hline
\end{tabular}




\begin{tabular}{|c|c|c|c|c|c|c|c|c|c|}
\hline \multirow[b]{2}{*}{ Patient } & \multirow[b]{2}{*}{ Order $^{a}$} & \multicolumn{4}{|c|}{$w=5, s=0.5$} & \multicolumn{4}{|c|}{$w=10, s=1$} \\
\hline & & $c_{\mathrm{S}(\mathbf{W})}$ & $c_{\mathrm{N}(\mathrm{W})}$ & $r_{\mathrm{N}} / r_{\mathrm{S}}$ & Selection $^{\mathrm{b}}$ & $c_{\mathrm{S}(\mathbf{W})}$ & $c_{\mathrm{N}(\mathrm{W})}$ & $r_{\mathrm{N}(} r_{\mathrm{S}}$ & Selection \\
\hline & 33 & 1.270 & 3.727 & 1.276 & & & & & \\
\hline & 34 & 0.854 & 2.960 & 1.507 & & & & & \\
\hline & 35 & 0.438 & 2.193 & 2.179 & & & & & \\
\hline & 36 & 0.252 & 1.851 & 3.196 & & & & & \\
\hline & 37 & 0.252 & 1.851 & 3.196 & & & & & \\
\hline & 38 & 0.252 & 1.851 & 3.196 & & & & & \\
\hline & 39 & 0.252 & 1.851 & 3.196 & & & & & \\
\hline & 40 & 0.252 & 1.851 & 3.196 & & & & & \\
\hline & 41 & 0.252 & 1.851 & 3.196 & & & & & \\
\hline & 42 & 0.252 & 1.851 & 3.196 & & & & & \\
\hline & 43 & 0.252 & 1.851 & 3.196 & & & & & \\
\hline & 44 & 0.252 & 1.851 & 3.196 & & & & & \\
\hline & 45 & 0.252 & 1.851 & 3.196 & & & & & \\
\hline & 46 & 0.252 & 1.851 & 3.196 & & & & & \\
\hline & 47 & 0.252 & 1.851 & 3.196 & & & & & \\
\hline & 48 & 0.252 & 1.851 & 3.196 & & & & & \\
\hline & 49 & 0.252 & 1.851 & 3.196 & & & & & \\
\hline & 50 & 0.252 & 1.851 & 3.196 & & & & & \\
\hline & 51 & 0.252 & 1.851 & 3.196 & & & & & \\
\hline 3 & 1 & 1.304 & 1.467 & 0.491 & & 3.063 & 9.802 & 1.396 & \\
\hline & 2 & 1.222 & 1.374 & 0.491 & & 2.818 & 11.696 & 1.810 & \\
\hline & 3 & 1.140 & 1.282 & 0.491 & & 2.573 & 13.208 & 2.239 & \\
\hline & 4 & 1.058 & 1.190 & 0.491 & & 2.337 & 14.437 & 2.693 & \\
\hline & 5 & 0.975 & 1.097 & 0.491 & & 2.235 & 15.627 & 3.048 & \\
\hline & 6 & 0.893 & 1.005 & 0.491 & & 2.125 & 16.345 & 3.354 & \\
\hline & 7 & 0.821 & 0.923 & 0.491 & & 2.015 & 17.028 & 3.685 & \\
\hline & 8 & 0.821 & 0.923 & 0.491 & & 2.100 & 17.161 & 3.563 & \\
\hline & 9 & 0.821 & 0.923 & 0.491 & & 2.194 & 17.294 & 3.437 & \\
\hline & 10 & 1.800 & 7.296 & 1.768 & & 2.323 & 19.132 & 3.592 & \\
\hline & 11 & 1.759 & 8.335 & 2.066 & & 1.976 & 12.405 & 2.738 & \\
\hline & 12 & 1.719 & 9.375 & 2.379 & & 2.604 & 10.974 & 1.838 & \\
\hline & 13 & 1.678 & 10.414 & 2.706 & & 2.535 & 9.303 & 1.600 & \\
\hline & 14 & 1.638 & 11.409 & 3.038 & & 2.787 & 7.715 & 1.207 & \\
\hline & 15 & 1.597 & 12.110 & 3.306 & & 3.060 & 7.325 & 1.044 & \\
\hline & 16 & 1.557 & 12.812 & 3.588 & & & & & \\
\hline & 17 & 1.517 & 13.514 & 3.886 & & & & & \\
\hline & 18 & 1.470 & 14.202 & 4.214 & $*$ & & & & \\
\hline
\end{tabular}


(Table S4). Contd.....

\begin{tabular}{|c|c|c|c|c|c|c|c|c|c|}
\hline \multirow[b]{2}{*}{ Patient } & \multirow[b]{2}{*}{ Order $^{a}$} & \multicolumn{4}{|c|}{$w=5, s=0.5$} & \multicolumn{4}{|c|}{$w=10, s=1$} \\
\hline & & $c_{\mathrm{S}(\mathbf{W})}$ & $c_{\mathrm{N}(\mathrm{W})}$ & $r_{N} / r_{S}$ & Selection $^{\mathbf{b}}$ & $c_{\mathrm{S}(\mathbf{W})}$ & $c_{\mathrm{N}(\mathrm{W})}$ & $r_{\mathrm{N}\left(r_{\mathrm{S}}\right.}$ & Selection \\
\hline & 19 & 1.415 & 14.704 & 4.533 & $*$ & & & & \\
\hline & 20 & 0.381 & 8.690 & 9.952 & & & & & \\
\hline & 21 & 0.366 & 8.009 & 9.539 & & & & & \\
\hline & 22 & 0.351 & 7.329 & 9.093 & & & & & \\
\hline & 23 & 0.337 & 6.614 & 8.563 & & & & & \\
\hline & 24 & 0.416 & 5.686 & 5.967 & & & & & \\
\hline & 25 & 0.503 & 5.051 & 4.379 & & & & & \\
\hline & 26 & 0.590 & 4.416 & 3.262 & & & & & \\
\hline & 27 & 0.678 & 3.781 & 2.433 & & & & & \\
\hline & 28 & 0.772 & 3.159 & 1.785 & & & & & \\
\hline & 29 & 0.908 & 4.429 & 2.126 & & & & & \\
\hline & 30 & 1.259 & 4.412 & 1.528 & & & & & \\
\hline & 31 & 1.610 & 4.396 & 1.191 & & & & & \\
\hline & 32 & 1.960 & 4.380 & 0.974 & & & & & \\
\hline & 33 & 2.267 & 4.360 & 0.839 & & & & & \\
\hline & 34 & 2.147 & 4.311 & 0.876 & & & & & \\
\hline & 35 & 2.032 & 4.253 & 0.913 & & & & & \\
\hline & 36 & 2.071 & 4.094 & 0.862 & & & & & \\
\hline & 37 & 2.109 & 3.935 & 0.814 & & & & & \\
\hline & 38 & 2.147 & 4.221 & 0.857 & & & & & \\
\hline & 39 & 2.151 & 2.897 & 0.587 & & & & & \\
\hline & 40 & 2.123 & 3.364 & 0.691 & & & & & \\
\hline 4 & 1 & 0.000 & 1.843 & $\infty$ & & 0.000 & 3.685 & $\infty$ & \\
\hline & 2 & 0.000 & 1.843 & $\infty$ & & 0.000 & 3.685 & $\infty$ & \\
\hline & 3 & 0.000 & 1.843 & $\infty$ & & 0.000 & 3.685 & $\infty$ & \\
\hline & 4 & 0.000 & 1.843 & $\infty$ & & 0.000 & 3.685 & $\infty$ & \\
\hline & 5 & 0.000 & 1.843 & $\infty$ & & 0.000 & 3.960 & $\infty$ & \\
\hline & 6 & 0.000 & 1.843 & $\infty$ & & 0.000 & 5.439 & $\infty$ & \\
\hline & 7 & 0.000 & 1.843 & $\infty$ & & 0.000 & 6.757 & $\infty$ & \\
\hline & 8 & 0.000 & 1.843 & $\infty$ & & 0.000 & 8.052 & $\infty$ & \\
\hline & 9 & 0.000 & 1.843 & $\infty$ & & 0.000 & 9.347 & $\infty$ & \\
\hline & 10 & 0.000 & 1.843 & $\infty$ & & 0.000 & 10.641 & $\infty$ & $*$ \\
\hline & 11 & 0.000 & 1.843 & $\infty$ & & 0.000 & 11.061 & $\infty$ & $*$ \\
\hline & 12 & 0.000 & 1.843 & $\infty$ & & 0.000 & 11.352 & $\infty$ & $*$ \\
\hline & 13 & 0.000 & 1.843 & $\infty$ & & 0.000 & 11.643 & $\infty$ & $*$ \\
\hline & 14 & 0.000 & 1.843 & $\infty$ & & 0.000 & 11.934 & $\infty$ & $*$ \\
\hline & 15 & 0.000 & 1.843 & $\infty$ & & 0.000 & 11.566 & $\infty$ & $*$ \\
\hline
\end{tabular}




\begin{tabular}{|c|c|c|c|c|c|c|c|c|c|}
\hline \multirow[b]{2}{*}{ Patient } & \multirow[b]{2}{*}{ Order $^{\mathrm{a}}$} & \multicolumn{4}{|c|}{$w=5, s=0.5$} & \multicolumn{4}{|c|}{$w=10, s=1$} \\
\hline & & $c_{\mathrm{S}(\mathbf{W})}$ & $c_{\mathrm{N}(\mathrm{W})}$ & $r_{\mathrm{N}} / r_{\mathrm{S}}$ & Selection $^{\mathrm{b}}$ & $c_{\mathrm{S}(\mathbf{W})}$ & $c_{\mathrm{N}(\mathrm{W})}$ & $r_{\mathrm{N}(} r_{\mathrm{S}}$ & Selection \\
\hline & 16 & 0.000 & 1.843 & $\infty$ & & 0.000 & 9.719 & $\infty$ & $*$ \\
\hline & 17 & 0.000 & 1.843 & $\infty$ & & 0.000 & 8.032 & $\infty$ & \\
\hline & 18 & 0.000 & 1.843 & $\infty$ & & 0.000 & 6.369 & $\infty$ & \\
\hline & 19 & 0.000 & 2.117 & $\infty$ & & 0.000 & 4.705 & $\infty$ & \\
\hline & 20 & 0.000 & 2.857 & $\infty$ & & 0.000 & 3.216 & $\infty$ & \\
\hline & 21 & 0.000 & 3.596 & $\infty$ & & 0.000 & 2.628 & $\infty$ & \\
\hline & 22 & 0.000 & 4.267 & $\infty$ & & 0.000 & 2.168 & $\infty$ & \\
\hline & 23 & 0.000 & 4.914 & $\infty$ & & 0.000 & 1.708 & $\infty$ & \\
\hline & 24 & 0.000 & 5.562 & $\infty$ & & 0.000 & 1.249 & $\infty$ & \\
\hline & 25 & 0.000 & 6.209 & $\infty$ & & & & & \\
\hline & 26 & 0.000 & 6.857 & $\infty$ & & & & & \\
\hline & 27 & 0.000 & 7.504 & $\infty$ & & & & & \\
\hline & 28 & 0.000 & 8.151 & $\infty$ & & & & & \\
\hline & 29 & 0.000 & 8.524 & $\infty$ & & & & & \\
\hline & 30 & 0.000 & 8.059 & $\infty$ & & & & & \\
\hline & 31 & 0.000 & 7.465 & $\infty$ & & & & & \\
\hline & 32 & 0.000 & 6.940 & $\infty$ & & & & & \\
\hline & 33 & 0.000 & 6.438 & $\infty$ & & & & & \\
\hline & 34 & 0.000 & 5.936 & $\infty$ & & & & & \\
\hline & 35 & 0.000 & 5.434 & $\infty$ & & & & & \\
\hline & 36 & 0.000 & 4.932 & $\infty$ & & & & & \\
\hline & 37 & 0.000 & 4.430 & $\infty$ & & & & & \\
\hline & 38 & 0.000 & 3.873 & $\infty$ & & & & & \\
\hline & 39 & 0.000 & 3.042 & $\infty$ & & & & & \\
\hline & 40 & 0.000 & 2.583 & $\infty$ & & & & & \\
\hline & 41 & 0.000 & 2.253 & $\infty$ & & & & & \\
\hline & 42 & 0.000 & 1.924 & $\infty$ & & & & & \\
\hline & 43 & 0.000 & 1.594 & $\infty$ & & & & & \\
\hline & 44 & 0.000 & 1.264 & $\infty$ & & & & & \\
\hline & 45 & 0.000 & 0.934 & $\infty$ & & & & & \\
\hline & 46 & 0.000 & 0.604 & $\infty$ & & & & & \\
\hline & 47 & 0.000 & 0.275 & $\infty$ & & & & & \\
\hline & 48 & 0.000 & 0.074 & $\infty$ & & & & & \\
\hline & 49 & 0.000 & 0.174 & $\infty$ & & & & & \\
\hline & 50 & 0.000 & 0.274 & $\infty$ & & & & & \\
\hline & 51 & 0.000 & 0.374 & $\infty$ & & & & & \\
\hline & 52 & 0.000 & 0.474 & $\infty$ & & & & & \\
\hline
\end{tabular}


(Table S4). Contd.....

\begin{tabular}{|c|c|c|c|c|c|c|c|c|c|}
\hline \multirow[b]{2}{*}{ Patient } & \multirow[b]{2}{*}{ Order $^{\mathrm{a}}$} & \multicolumn{4}{|c|}{$w=5, s=0.5$} & \multicolumn{4}{|c|}{$w=10, s=1$} \\
\hline & & $c_{\mathrm{S}(\mathbf{W})}$ & $c_{\mathrm{N}(\mathrm{W})}$ & $r_{\mathrm{N}} / r_{\mathrm{S}}$ & Selection $^{\mathbf{b}}$ & $c_{\mathrm{S}(\mathbf{W})}$ & $c_{\mathrm{N}(\mathbf{W})}$ & $r_{\mathrm{N}(} r_{\mathrm{S}}$ & Selection \\
\hline & 53 & 0.000 & 0.574 & $\infty$ & & & & & \\
\hline & 54 & 0.000 & 0.674 & $\infty$ & & & & & \\
\hline & 55 & 0.000 & 0.774 & $\infty$ & & & & & \\
\hline & 56 & 0.000 & 0.874 & $\infty$ & & & & & \\
\hline & 57 & 0.000 & 0.974 & $\infty$ & & & & & \\
\hline 5 & 1 & 0.365 & 2.919 & 3.421 & & 1.930 & 14.771 & 3.272 & \\
\hline & 2 & 0.365 & 2.919 & 3.421 & & 2.038 & 15.874 & 3.330 & \\
\hline & 3 & 0.365 & 2.919 & 3.421 & & 2.146 & 16.976 & 3.382 & \\
\hline & 4 & 0.365 & 2.919 & 3.421 & & 2.254 & 18.079 & 3.429 & \\
\hline & 5 & 0.365 & 2.919 & 3.421 & & 2.362 & 18.579 & 3.363 & \\
\hline & 6 & 1.295 & 9.095 & 3.002 & $*$ & 2.470 & 19.032 & 3.294 & \\
\hline & 7 & 1.349 & 9.646 & 3.056 & $*$ & 2.578 & 19.484 & 3.231 & \\
\hline & 8 & 1.403 & 10.198 & 3.107 & $*$ & 2.686 & 19.937 & 3.173 & \\
\hline & 9 & 1.457 & 10.749 & 3.153 & $*$ & 1.810 & 13.662 & 3.228 & \\
\hline & 10 & 1.511 & 11.300 & 3.197 & $*$ & 1.810 & 13.012 & 3.074 & \\
\hline & 11 & 1.565 & 11.852 & 3.237 & $*$ & 1.810 & 12.362 & 2.921 & \\
\hline & 12 & 1.619 & 12.403 & 3.275 & $*$ & 3.121 & 31.413 & 4.303 & $*$ \\
\hline & 13 & 1.673 & 12.955 & 3.310 & $*$ & 3.483 & 32.363 & 3.973 & $*$ \\
\hline & 14 & 1.727 & 13.506 & 3.343 & $*$ & 3.721 & 32.995 & 3.792 & $*$ \\
\hline & 15 & 1.781 & 14.057 & 3.374 & $*$ & 3.949 & 34.204 & 3.704 & $*$ \\
\hline & 16 & 0.905 & 8.433 & 3.985 & & 4.176 & 35.462 & 3.630 & $*$ \\
\hline & 17 & 0.905 & 8.433 & 3.985 & & 4.404 & 36.719 & 3.565 & $*$ \\
\hline & 18 & 0.905 & 8.156 & 3.854 & & 4.632 & 37.976 & 3.505 & $*$ \\
\hline & 19 & 0.905 & 7.830 & 3.700 & & 4.639 & 37.432 & 3.450 & $*$ \\
\hline & 20 & 0.905 & 7.505 & 3.547 & & 4.628 & 36.608 & 3.383 & $*$ \\
\hline & 21 & 0.905 & 7.180 & 3.393 & & 4.616 & 35.763 & 3.312 & $*$ \\
\hline & 22 & 0.905 & 6.855 & 3.239 & & 3.294 & 15.216 & 1.975 & \\
\hline & 23 & 0.905 & 6.530 & 3.086 & & 2.921 & 12.771 & 1.870 & \\
\hline & 24 & 0.905 & 6.205 & 2.932 & & & & & \\
\hline & 25 & 0.905 & 5.880 & 2.778 & & & & & \\
\hline & 26 & 0.905 & 5.555 & 2.625 & & & & & \\
\hline & 27 & 0.905 & 5.229 & 2.471 & & & & & \\
\hline & 28 & 0.905 & 5.182 & 2.449 & & & & & \\
\hline & 29 & 0.905 & 5.182 & 2.449 & & & & & \\
\hline & 30 & 0.905 & 5.182 & 2.449 & & & & & \\
\hline & 31 & 0.905 & 5.182 & 2.449 & & & & & \\
\hline & 32 & 2.035 & 24.083 & 5.059 & & & & & \\
\hline
\end{tabular}




\begin{tabular}{|c|c|c|c|c|c|c|c|c|c|}
\hline \multirow[b]{2}{*}{ Patient } & \multirow[b]{2}{*}{ Order $^{a}$} & \multicolumn{4}{|c|}{$w=5, s=0.5$} & \multicolumn{4}{|c|}{$w=10, s=1$} \\
\hline & & $c_{\mathrm{S}(\mathbf{W})}$ & $c_{\mathrm{N}(\mathrm{W})}$ & $r_{\mathrm{N}} / r_{\mathrm{S}}$ & Selection $^{\mathrm{b}}$ & $c_{\mathrm{S}(\mathbf{W})}$ & $c_{\mathrm{N}(\mathrm{W})}$ & $r_{\mathrm{N}(} r_{\mathrm{S}}$ & Selection \\
\hline & 33 & 2.216 & 24.883 & 4.801 & & & & & \\
\hline & 34 & 2.397 & 25.683 & 4.581 & & & & & \\
\hline & 35 & 2.578 & 26.483 & 4.392 & & & & & \\
\hline & 36 & 2.702 & 27.137 & 4.295 & & & & & \\
\hline & 37 & 2.816 & 27.765 & 4.216 & & & & & \\
\hline & 38 & 2.930 & 28.394 & 4.144 & & & & & \\
\hline & 39 & 3.044 & 29.023 & 4.077 & & & & & \\
\hline & 40 & 3.158 & 29.651 & 4.015 & & & & & \\
\hline & 41 & 3.272 & 30.280 & 3.957 & & & & & \\
\hline & 42 & 2.255 & 12.007 & 2.277 & & & & & \\
\hline & 43 & 2.188 & 11.836 & 2.313 & & & & & \\
\hline & 44 & 2.121 & 11.664 & 2.351 & & & & & \\
\hline & 45 & 2.054 & 11.493 & 2.392 & & & & & \\
\hline & 46 & 1.943 & 10.639 & 2.342 & & & & & \\
\hline & 47 & 1.823 & 9.667 & 2.267 & & & & & \\
\hline & 48 & 1.703 & 8.637 & 2.168 & & & & & \\
\hline & 49 & 1.584 & 7.586 & 2.048 & & & & & \\
\hline & 50 & 1.464 & 6.535 & 1.908 & & & & & \\
\hline & 51 & 1.345 & 5.483 & 1.744 & & & & & \\
\hline & 52 & 1.225 & 4.432 & 1.547 & & & & & \\
\hline & 53 & 1.106 & 3.381 & 1.308 & & & & & \\
\hline & 54 & 0.986 & 2.329 & 1.010 & & & & & \\
\hline & 55 & 0.866 & 1.278 & 0.631 & & & & & \\
\hline $1-5^{\mathrm{c}}$ & 1 & 2.511 & 16.349 & 2.818 & & 7.225 & 52.506 & 3.146 & $*$ \\
\hline & 2 & 2.430 & 16.801 & 2.993 & & 7.337 & 56.377 & 3.326 & $*$ \\
\hline & 3 & 2.349 & 17.253 & 3.179 & & 7.465 & 59.662 & 3.460 & $*$ \\
\hline & 4 & 2.268 & 17.705 & 3.379 & & 7.632 & 62.125 & 3.524 & $*$ \\
\hline & 5 & 2.187 & 18.157 & 3.594 & & 8.622 & 64.323 & 3.230 & $*$ \\
\hline & 6 & 3.037 & 24.784 & 3.533 & $*$ & 11.376 & 71.676 & 2.728 & $*$ \\
\hline & 7 & 3.019 & 25.657 & 3.679 & $*$ & 12.471 & 75.844 & 2.633 & $*$ \\
\hline & 8 & 3.073 & 26.208 & 3.692 & $*$ & 13.966 & 78.809 & 2.443 & $*$ \\
\hline & 9 & 3.127 & 26.760 & 3.705 & $*$ & 13.707 & 72.950 & 2.304 & $*$ \\
\hline & 10 & 4.577 & 34.672 & 3.280 & $*$ & 14.174 & 74.078 & 2.262 & $*$ \\
\hline & 11 & 4.714 & 36.156 & 3.320 & $*$ & 13.625 & 64.885 & 2.062 & $*$ \\
\hline & 12 & 4.851 & 37.640 & 3.359 & $*$ & 15.656 & 81.654 & 2.258 & $*$ \\
\hline & 13 & 4.988 & 39.125 & 3.395 & $*$ & 16.025 & 80.289 & 2.169 & $*$ \\
\hline & 14 & 5.125 & 40.564 & 3.426 & $*$ & 16.485 & 78.875 & 2.071 & $*$ \\
\hline
\end{tabular}


(Table S4). Contd.....

\begin{tabular}{|c|c|c|c|c|c|c|c|c|c|}
\hline \multirow[b]{2}{*}{ Patient } & \multirow[b]{2}{*}{ Order $^{\mathrm{a}}$} & \multicolumn{4}{|c|}{$w=5, s=0.5$} & \multicolumn{4}{|c|}{$w=10, s=1$} \\
\hline & & $c_{\mathrm{S}(\mathbf{W})}$ & $c_{\mathrm{N}(\mathrm{W})}$ & $r_{N} / r_{S}$ & Selection $^{\mathbf{b}}$ & $c_{\mathrm{S}(\mathbf{W})}$ & $c_{\mathrm{N}(\mathrm{W})}$ & $r_{\mathrm{N}(} r_{\mathrm{S}}$ & Selection \\
\hline & 15 & 5.278 & 41.505 & 3.404 & $*$ & 16.183 & 77.291 & 2.068 & $*$ \\
\hline & 16 & 4.507 & 36.174 & 3.474 & $*$ & 10.776 & 62.869 & 2.526 & $*$ \\
\hline & 17 & 4.613 & 36.468 & 3.422 & $*$ & 10.506 & 62.219 & 2.564 & $*$ \\
\hline & 18 & 4.713 & 36.470 & 3.350 & $*$ & 9.776 & 59.580 & 2.638 & $*$ \\
\hline & 19 & 5.495 & 37.563 & 2.959 & $*$ & 9.138 & 56.400 & 2.672 & $*$ \\
\hline & 20 & 4.424 & 31.055 & 3.039 & $*$ & 8.669 & 53.455 & 2.669 & $*$ \\
\hline & 21 & 6.662 & 35.520 & 2.308 & $*$ & 8.200 & 51.390 & 2.713 & $*$ \\
\hline & 22 & 7.031 & 36.072 & 2.221 & $*$ & 5.916 & 26.051 & 1.906 & $*$ \\
\hline & 23 & 7.482 & 36.720 & 2.124 & $*$ & 2.921 & 14.480 & 2.146 & \\
\hline & 24 & 8.143 & 37.165 & 1.976 & & 0.000 & 1.249 & $\infty$ & \\
\hline & 25 & 8.688 & 37.304 & 1.859 & & & & & \\
\hline & 26 & 8.984 & 37.064 & 1.786 & & & & & \\
\hline & 27 & 9.094 & 36.482 & 1.737 & & & & & \\
\hline & 28 & 9.211 & 36.191 & 1.701 & & & & & \\
\hline & 29 & 8.680 & 36.516 & 1.821 & & & & & \\
\hline & 30 & 8.820 & 35.276 & 1.731 & & & & & \\
\hline & 31 & 6.963 & 29.365 & 1.826 & & & & & \\
\hline & 32 & 8.107 & 46.267 & 2.471 & $*$ & & & & \\
\hline & 33 & 8.173 & 44.934 & 2.380 & $*$ & & & & \\
\hline & 34 & 7.698 & 43.562 & 2.450 & $*$ & & & & \\
\hline & 35 & 7.337 & 42.985 & 2.536 & $*$ & & & & \\
\hline & 36 & 7.313 & 42.635 & 2.524 & $*$ & & & & \\
\hline & 37 & 7.391 & 42.393 & 2.483 & $*$ & & & & \\
\hline & 38 & 7.465 & 42.527 & 2.466 & $*$ & & & & \\
\hline & 39 & 7.504 & 40.775 & 2.352 & $*$ & & & & \\
\hline & 40 & 7.510 & 41.189 & 2.374 & $*$ & & & & \\
\hline & 41 & 5.422 & 37.900 & 3.026 & $*$ & & & & \\
\hline & 42 & 4.458 & 20.808 & 2.020 & & & & & \\
\hline & 43 & 4.600 & 21.644 & 2.037 & & & & & \\
\hline & 44 & 4.741 & 21.619 & 1.974 & & & & & \\
\hline & 45 & 4.471 & 20.848 & 2.019 & & & & & \\
\hline & 46 & 4.130 & 19.348 & 2.028 & & & & & \\
\hline & 47 & 3.856 & 17.942 & 2.014 & & & & & \\
\hline & 48 & 3.586 & 16.620 & 2.006 & & & & & \\
\hline & 49 & 3.317 & 15.576 & 2.033 & & & & & \\
\hline & 50 & 3.047 & 14.533 & 2.065 & & & & & \\
\hline & 51 & 2.778 & 13.490 & 2.102 & & & & & \\
\hline
\end{tabular}


(Table S4). Contd....

\begin{tabular}{|c|c|c|c|c|c|c|c|c|c|}
\hline \multirow[b]{2}{*}{ Patient } & \multirow[b]{2}{*}{ Order $^{a}$} & \multicolumn{4}{|c|}{$w=5, s=0.5$} & \multicolumn{4}{|c|}{$w=10, s=1$} \\
\hline & & $c_{\mathrm{S}(\mathrm{W})}$ & $c_{\mathrm{N}(\mathbf{W})}$ & $r_{\mathrm{N}} / r_{\mathrm{S}}$ & Selection $^{b}$ & $c_{\mathrm{S}(\mathbf{W})}$ & $c_{\mathrm{N}(\mathbf{W})}$ & $r_{\mathrm{N}} r_{\mathrm{S}}$ & Selection \\
\hline & 52 & 2.125 & 8.862 & 1.805 & & & & & \\
\hline & 53 & 1.568 & 6.257 & 1.727 & & & & & \\
\hline & 54 & 1.011 & 4.515 & 1.932 & & & & & \\
\hline & 55 & 0.866 & 2.052 & 1.026 & & & & & \\
\hline & 56 & 0.000 & 0.874 & $\infty$ & & & & & \\
\hline & 57 & 0.000 & 0.974 & $\infty$ & & & & & \\
\hline
\end{tabular}

${ }^{\mathrm{a}}$ Phylogenetic windows are ordered chronologically.

${ }^{\mathrm{b}}$ Positively selected windows are indicated with black and red asterisks for $w=5$ and $w=10$, respectively.

${ }^{\mathrm{c}}$ The $c_{\mathrm{S}(\mathrm{W})}$ and $c_{\mathrm{N}(\mathrm{W})}$ values for the phylogenetic windows of the same chronological order were summed for patients 1-5. 